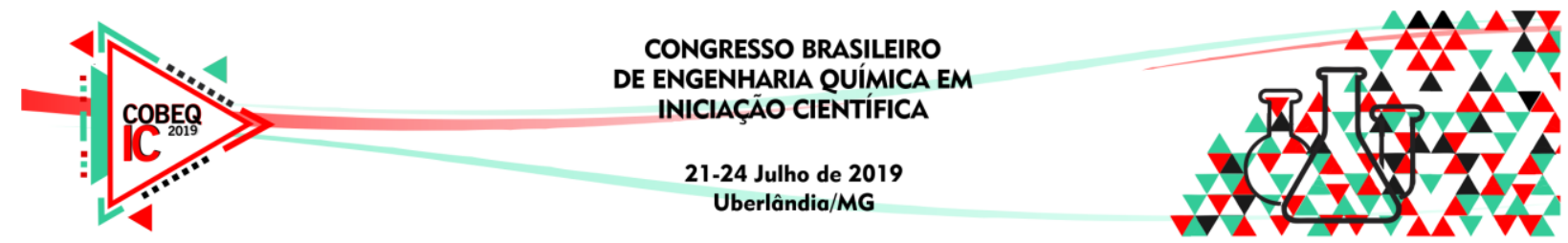

\title{
AVALIAÇÃO DO POTENCIAL DO PROCESSO DE DESTILAÇÃO POR MEMBRANA NA REMOÇÃ̃O DE ARSÊNIO E SULFATO DE EFLUENTE DE MINERAÇÃO DE OURO
}

\author{
M. R. SILVA ${ }^{2}$, A. P. B. ARAÚJO ${ }^{1}$, G. C. MOREIRA ${ }^{1}$ e M. C. S. AMARAL ${ }^{2}$ \\ ${ }^{1}$ Pontifícia Universidade Católica de Minas Gerais, Faculdade de Engenharia Química \\ ${ }^{2}$ Universidade Federal de Minas Gerais, Departamento de Engenharia Sanitária e Ambiental \\ E-mail para contato: alessandra.araujoo20@gmail.com
}

\begin{abstract}
RESUMO - A mineração do ouro é uma atividade de destaque econômico, tendo em vista a ampla aplicabilidade desse metal, contribuindo diretamente para o produto interno bruto brasileiro (PIB). Entretanto, a exploração do minério de ouro traz impactos ambientais, como a geração de efluentes altamente contaminados, associada ao elevado gasto de água nos processos. Diante do quadro de escassez presenciado nos últimos anos, assim como pelas legislações ambientais cada vez mais restritivas, a conscientização pelo uso racional da água e a busca por mudanças dentro das indústrias, no quesito de tratamento de efluentes, vêm sendo questionada. Dentre as técnicas disponíveis têm-se mostrado promissores os processos de separação por membranas, como a destilação assistida por membranas (DM). Isto posto, o presente estudo teve como objetivo avaliar a remoção de sulfato e arsênio do efluente da planta de produção de ácido sulfúrico, proveniente da mineração de ouro, empregando destilação por membrana. Nesse trabalho, o sistema de DM foi aplicado a águas residuárias brutas e pré-tratadas por ultrafiltração e ajuste de $\mathrm{pH}$, com o intuito de avaliar a incrustação da membrana e a qualidade do efluente tratado em decorrência da remoção de seus contaminantes. Os resultados mostraram que a aplicação do pré-tratamento por ultrafiltração reduz o potencial de incrustação da membrana, assim como o processo de DM alcançou elevadas remoções dos contaminantes presentes na matriz do efluente.
\end{abstract}

\section{INTRODUÇÃO}

Um dos grandes desafios de muitas indústrias é conciliar suas vantagens econômicas com os impactos ambientais causados durante sua operação. A título de exemplo tem-se a mineração que possui relevância para a economia do Brasil, visto que cresce e se desenvolve no território, diante do potencial do solo brasileiro, o qual possui características atípicas e ricas. Porém, associado a esse crescimento econômico, destacam-se os debates em torno dos impactos ambientais provocados por essa atividade, sendo relevante o estudo e a aplicação do desenvolvimento sustentável.

O processo de mineração do ouro consiste desde a exploração do minério até o seu beneficiamento. Uma etapa comum no processo de beneficiamento pirometalúrgico do ouro é a ustulação, a qual gera um efluente de caráter ácido, contaminado com metais pesados e substâncias corrosivas, bem como apresenta alta concentração de arsênio em sua matriz. Desse modo, o lançamento inadequado deste efluente em corpos hídricos resulta em danos 


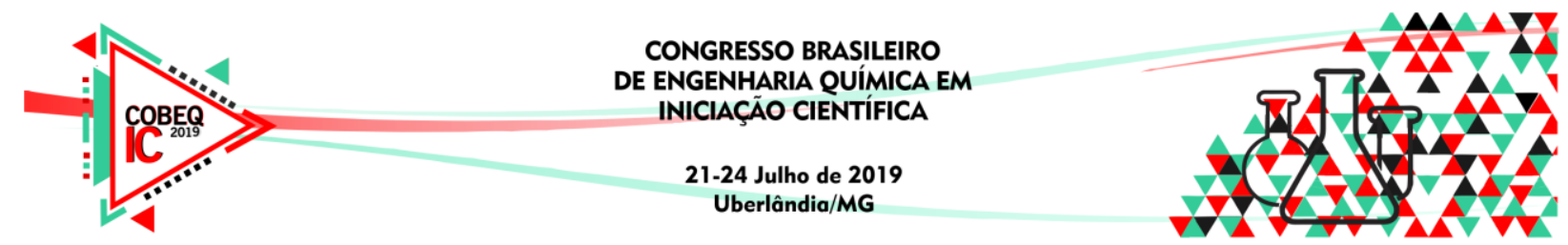

ambientais severos, diante da elevada toxicidade desses poluentes tanto para os seres vivos quanto para o ambiente, evidenciando a necessidade da aplicação de um tratamento.

Os processos de separação por membranas (PSM) são sistemas que utilizam uma membrana como barreira seletiva para promover a separação de duas fases de uma dada solução, por meio da ação de uma força-motriz. Estudos recentes focados no desenvolvimento desse processo têm demonstrado a atratividade em torno da aplicação desta tecnologia para o tratamento avançado de efluentes, frente à possibilidade do reúso da água no processo industrial (KUNZ, PERALTA-ZAMORA, 2002).

A DM é um tipo de PSM considerado relativamente novo que vem sendo investigado e tem despertado o interesse de acadêmicos e cientistas por ser uma alternativa de baixo custo e econômica energeticamente, se comparada aos processos convencionais de separação (DRIOLI et $a l .$, 2015). Essa técnica consiste no uso de uma membrana microporosa e hidrofóbica, pela qual somente moléculas de vapor se difundem. Para tanto, essa transferência de massa ocorre mediante a ação de uma força-motriz advinda da diferença de pressão de vapor existente na membrana. Essa diferença de pressão resulta de um gradiente de temperatura entre a alimentação (solução aquecida) e o permeado (solução à temperatura ambiente). Dessa forma, o objetivo deste estudo foi avaliar a aplicação da DM para a remoção de contaminantes, como arsênio e sulfato, de efluente da planta de produção de ácido sulfúrico de uma empresa de mineração de ouro.

\section{MATERIAIS E MÉTODOS}

\subsection{Amostras}

Para a realização dos experimentos foi utilizado o efluente de uma mineradora de ouro localizada em Minas Gerais. Esse efluente caracteriza-se por elevadas concentrações de sulfato, cálcio, magnésio, arsênio, assim como por seu pH ácido e por uma elevada temperatura, de aproximadamente $80{ }^{\circ} \mathrm{C}$, o que favorece o processo de destilação, uma vez que o calor residual do próprio efluente pode ser aproveitado para aquecer o sistema.

\subsection{Descrição do pré-tratamento}

A amostra coletada foi submetida a um pré-tratamento por ultrafiltração (UF) e ajuste de $\mathrm{pH}$, com a finalidade de avaliar a influência deste na incrustação da membrana utilizada no sistema de DM, bem como maximizar sua vida útil e dos demais componentes do sistema. $\mathrm{O}$ módulo de UF utilizado foi o GE-ZeeWeed1-3, com diâmetro de poro nominal de 0,04 $\mu \mathrm{m}$ e área de filtração equivalente a $0,047 \mathrm{~m}^{2}$. O pré-tratamento aplicado consistiu inicialmente no ajuste de pH do efluente bruto para 3, 4 e 5, seguido da ultrafiltração de cada amostra obtida. Uma amostra ultrafiltrada do efluente bruto sem correção de $\mathrm{pH}$ também foi gerada e, posteriormente, encaminhada para a alimentação do teste de DM juntamente com os demais permeados obtidos e o efluente bruto sem nenhum tipo de pré-tratamento. 


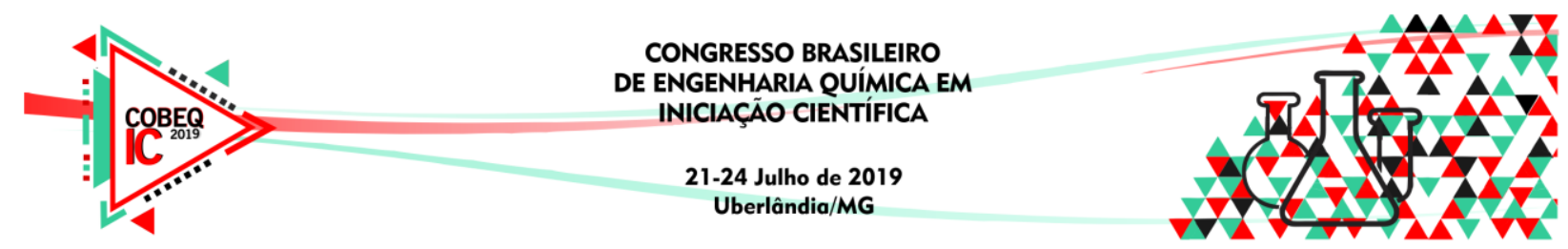

\subsection{Descrição dos ensaios de destilação}

Os ensaios foram conduzidos em escala laboratorial por meio de uma unidade experimental constituída de tanque de alimentação e permeado, medidores de condutividade e temperatura, sistemas de aquecimento e resfriamento, balança digital, bombas de circulação e por um módulo de DM composto por uma membrana plana PTFE Laminated Membrane da STERLITECH, com diâmetro de poro de $0,2 \mu \mathrm{m}$. A execução dos experimentos se deu diante do preenchimento do tanque de alimentação com $1,5 \mathrm{~L}$ de efluente, cuja temperatura foi mantida em $60{ }^{\circ} \mathrm{C}$. Outrossim, o tanque de permeado foi preenchido com 1,5 L de água destilada, sendo a temperatura desse tanque mantida em $25^{\circ} \mathrm{C}$. O sistema montado foi operado por oito horas em modo contracorrente, com uma vazão de $0,5 \mathrm{~L} / \mathrm{min}$ e monitoramento da condutividade, temperatura e $\mathrm{pH}$ da alimentação e do permeado, assim como da massa do permeado.

\subsection{Caracterização das amostras}

A fim de conhecer a amostra trabalhada, avaliar a aplicação do pré-tratamento e verificar a eficiência do processo de DM, foi efetuada a caracterização do efluente bruto e pré-tratado, assim como dos permeados e concentrados obtidos. Tal caracterização foi realizada a partir de parâmetros físico-químicos, como $\mathrm{pH}$, condutividade, sólidos totais, sulfato, cloreto, cálcio e magnésio, de acordo com o Standard Methods for Examination of Water and Wastewater. Ademais, a análise de arsênio (DHAR et al., 2014) também foi realizada, tendo em vista a elevada concentração desse contaminante no efluente e o objetivo do trabalho em torno de sua remoção e do sulfato.

\subsection{Avaliação da taxa de recuperação}

Ao final das etapas, a taxa de recuperação máxima foi avaliada, sendo esta medida a partir do percentual da alimentação que efetivamente se converteu em permeado, sem que houvesse a redução de sua qualidade, bem como o decaimento do fluxo ocasionado pela incrustação da membrana. Para tanto, foi realizado o teste de incrustação da membrana

\section{RESULTADOS E DISCUSSÃO}

\subsection{Avaliação geral do desempenho do processo de destilação por membranas}

A eficiência geral do processo de DM foi avaliada utilizando como alimentação o efluente de mineração de ouro sem a etapa de pré-tratamento. Ao longo do intervalo analisado, observou-se que à medida que a massa de permeado aumentava a condutividade e o $\mathrm{pH}$ permaneciam próximos aos valores iniciais que seriam os valores referentes à água destilada. Sendo assim, constata-se que a membrana agiu como uma barreira impedindo a passagem dos contaminantes e, por consequência, mantendo a qualidade do permeado. Ademais, o fluxo de permeado permaneceu em valores próximos a $10,0 \mathrm{Kg} \cdot \mathrm{m}^{-2} \cdot \mathrm{h}^{-1}$ e a taxa de recuperação foi aproximadamente $20 \%$, como demonstrado na Figura 1 . No entanto, é válido ressaltar que essa taxa não representa à máxima, pois não houve um acentuado decaimento no fluxo e nem uma perda na qualidade do permeado. 


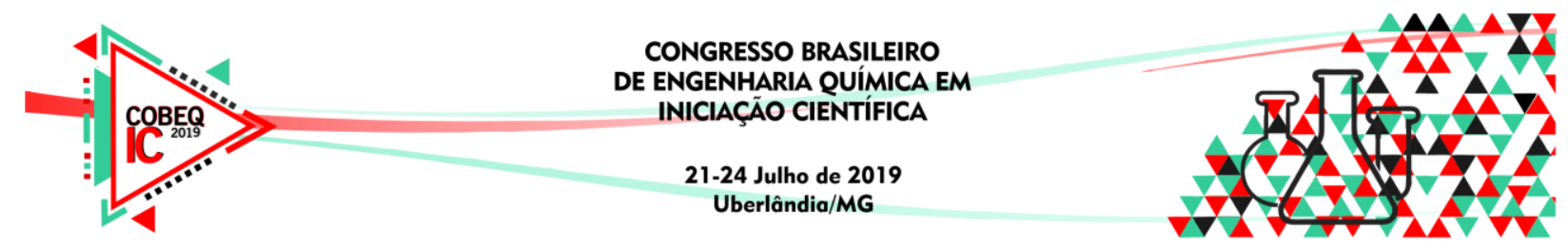

Figura 1 - Relação entre fluxo de permeado e grau de recuperação.

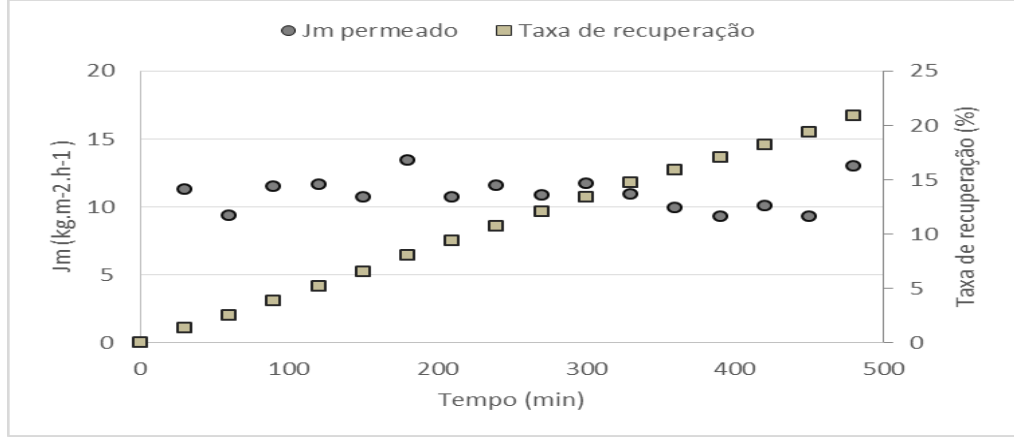

Os resultados obtidos para as análises físico-químicas da alimentação, concentrado e permeado, assim como a rejeição dos contaminantes, estão apresentados na Tabela 1. Observa-se que o processo promoveu elevadas remoções dos contaminantes, além de remover todo sulfato e $99,9 \%$ de arsênio total. Esses resultados estão de acordo com o estudo feito por Qu et al. (2009) que obtiveram rejeição superior a 99\% de arsênio e constataram que o processo de destilação assistida por membranas por contato direto promove altas remoções de cátions e ânions, sem seleção entre íons monovalentes e divalentes.

Tabela 1 - Eficiência de retenção de poluentes na membrana

\begin{tabular}{c|cccc}
\hline & Alimentação & Permeado & Concentrado & Rejeição \% \\
\hline Arsênio total $(\mathrm{mg} / \mathrm{L})$ & 270 & 0,14 & 601 & 99,9 \\
Sulfato $(\mathrm{mg} / \mathrm{L})$ & 2418 & $<\mathrm{LD}$ & 8350 & 100,0 \\
Cloreto $(\mathrm{mg} / \mathrm{L})$ & 67 & $<\mathrm{LD}$ & 91 & 100,0 \\
Cálcio $(\mathrm{mg} / \mathrm{L})$ & 386 & 1,29 & 606 & 99,7 \\
Magnésio $(\mathrm{mg} / \mathrm{L})$ & 385 & $<\mathrm{LD}$ & 767 & 100,0 \\
Sólidos totais $(\mathrm{mg} / \mathrm{L})$ & 6622 & $<\mathrm{LD}$ & 11372 & 100,0 \\
Condutividade $(\mu \mathrm{S} / \mathrm{cm})$ & 17960 & 6,99 & 23090 & 100,0 \\
\hline
\end{tabular}

*LD: Limite de detecção.

\subsection{Influência do pré-tratamento da alimentação no fluxo do permeado}

A fim de melhor analisar o decaimento do fluxo em função da taxa de recuperação foi construído um gráfico, como apresentado na Figura 2. Para facilitar o entendimento, considerou-se que T1 é referente à alimentação com efluente bruto sem pré-tratamento, T2 o efluente ultrafiltrado sem correção de $\mathrm{pH}, \mathrm{T} 3, \mathrm{~T} 4$ e T5 o efluente ultrafiltrado após ajuste do pH para 3, 4 e 5, respectivamente. Pode-se observar que a taxa de recuperação atingida para todos os testes foi de aproximadamente $25 \%$. Além disso, verifica-se que para T3, T4 e T5 houve um decaimento do fluxo. 


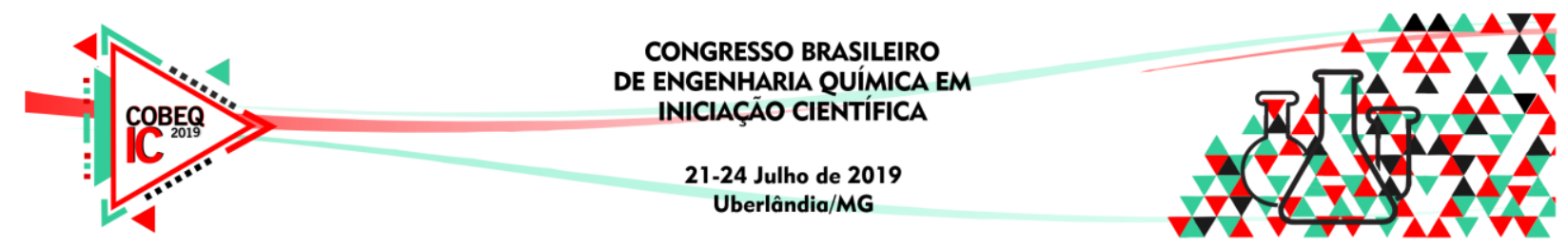

Figura 2 - Taxa de recuperação e o fluxo de permeado para os testes de DM.

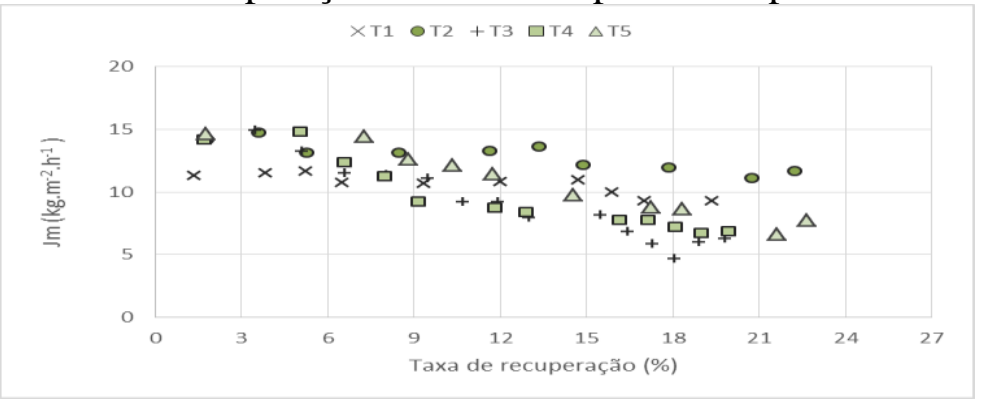

A eficiência de remoção dos contaminantes para a alimentação, concentrado e permeado dos cinco testes podem ser encontradas na Tabela 2. Verifica-se que o desempenho de remoção dos contaminantes analisados foi semelhante entre os testes avaliados. Desse modo, a alimentação selecionada como ideal para avaliação da taxa de incrustação foi o efluente ultrafiltrado sem correção de $\mathrm{pH}$, pois apresentou um bom desempenho nas análises físicoquímicas. Além disso, a ultrafiltração pode maximizar a vida útil da membrana e dos demais componentes do sistema, uma vez que promove a remoção do excesso de sais e a degradação de moléculas orgânicas com alta tendência à incrustação.

Tabela 2 - Percentual de rejeições dos contaminantes avaliados para os testes sem (T1) e com pré-tratamento (T2, T3, T4, T5)

\begin{tabular}{l|ccccc}
\hline & $\mathrm{T} 1(\%)$ & $\mathrm{T} 2(\%)$ & $\mathrm{T} 3(\%)$ & $\mathrm{T} 4(\%)$ & $\mathrm{T} 5(\%)$ \\
\hline Arsênio total $(\mathrm{mg} / \mathrm{L})$ & 99,9 & 100,0 & 99,8 & 99,9 & 100,0 \\
Arsênio 5 $(\mathrm{mg} / \mathrm{L})$ & 99,9 & 100,0 & 99,3 & 100,0 & 100,0 \\
Arsênio 3 $(\mathrm{m} / \mathrm{L})$ & 100,0 & 100,0 & 100,0 & 99,8 & 100,0 \\
Sulfato $(\mathrm{mg} / \mathrm{L})$ & 100,0 & 100,0 & 100,0 & 100,0 & 100,0 \\
Cloreto $(\mathrm{mg} / \mathrm{L})$ & 100,0 & 100,0 & 100,0 & 100,0 & 100,0 \\
Cálcio $(\mathrm{mg} / \mathrm{L})$ & 99,7 & 99,8 & 99,8 & 99,8 & 99,8 \\
Magnésio $(\mathrm{mg} / \mathrm{L})$ & 100,0 & 100,0 & 100,0 & 99,9 & 100,0 \\
Sólidos totais $(\mathrm{mg} / \mathrm{L})$ & 100,0 & 100,0 & 100,0 & 100,0 & 100,0 \\
Condutividade $(\mu \mathrm{S} / \mathrm{cm})$ & 100,0 & 100,0 & 99,9 & 99,8 & 99,9 \\
\hline
\end{tabular}

\subsection{Teste de incrustação da membrana}

O teste foi realizado por 84 horas e obteve uma taxa de recuperação de aproximadamente $90 \%$. Como pode ser observado na Figura 3, o fluxo de permeado foi diminuindo ao longo do tempo, atingindo a metade $\left(10 \mathrm{Kg} \cdot \mathrm{m}^{-2} \cdot \mathrm{h}^{-1}\right)$ em 1000 minutos. Vale ressaltar que até esse período a taxa de recuperação foi de $30 \%$ e, o pH e a condutividade sofreram uma pequena variação, de 8 a 6 e de 4 a $6 \mu \mathrm{S} / \mathrm{cm}$, respectivamente.

Em relação ao monitoramento do permeado foi observado aumento da condutividade e redução do $\mathrm{pH}$. Essa alteração da qualidade do permeado pode ter sido influenciada pelo molhamento da membrana, pois como no período noturno o teste permaneceu desligado, o vapor de água que estava presente na interface da membrana condensou e propiciou o molhamento da mesma. Para mais, a redução do fluxo de permeado pode estar relacionada com a deposição de sais na superfície da membrana, provavelmente ocasionada pela precipitação do sulfato de cálcio. Esse efeito pode ser decorrente de uma condição de 


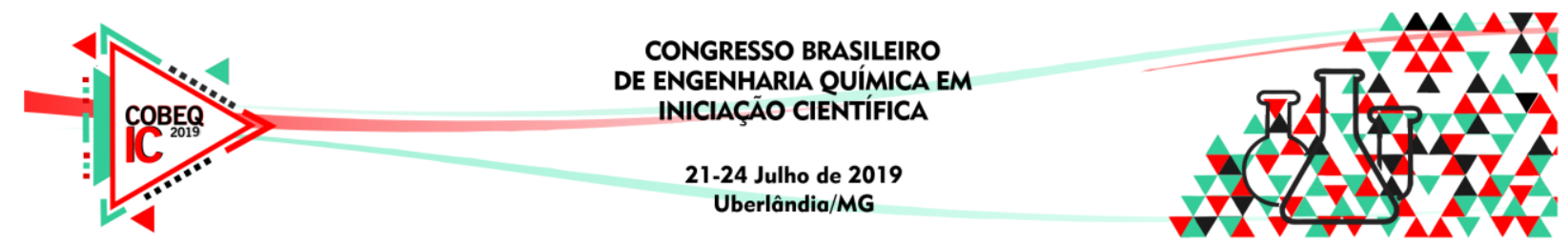

supersaturação no efluente. Desse modo, a resistência térmica adicional foi favorecida e aumentou a polarização da temperatura. Por conseguinte, promoveu a redução da força motriz e da área disponível para vaporização de água.

Figura 3 - Avaliação ao longo do tempo: (a) do fluxo de permeado e da taxa de recuperação (b) da condutividade e do $\mathrm{pH}$.

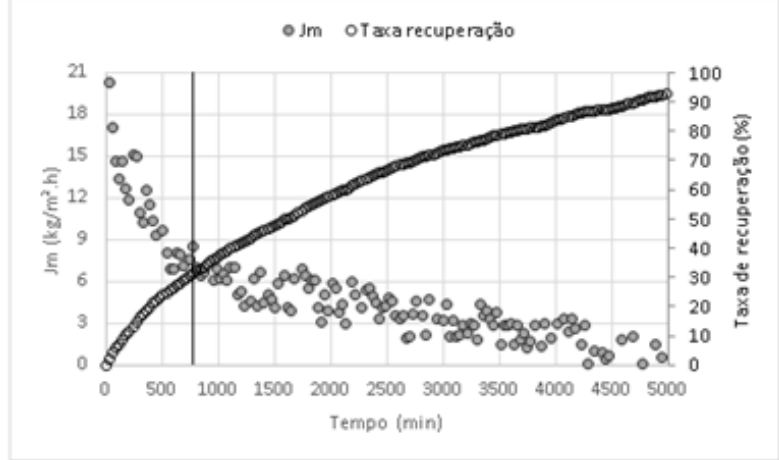

(a)

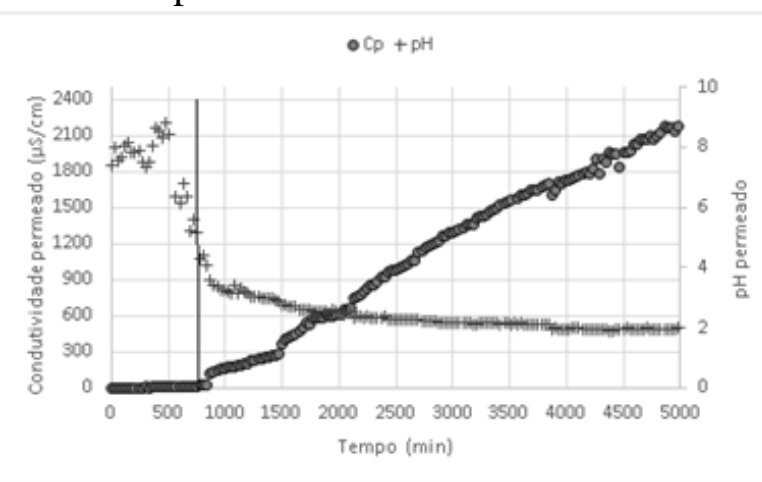

(b)

\section{CONCLUSÃO}

Diante do exposto, pode-se dizer que o processo de destilação por membranas por contato direto é uma alternativa interessante para o tratamento de efluente de mineradora de ouro, uma vez que promoveu altas remoções de sulfato e arsênio, bem como dos demais contaminantes. Além disso, como o efluente apresenta elevada temperatura, aproximadamente $80^{\circ} \mathrm{C}$, a destilação é favorecida, visto que o calor residual poderá ser aproveitado para aquecer o sistema, o que reduz os custos do processo. Outrossim, nota-se que a associação da ultrafiltração com DM é a alternativa mais viável, tendo em vista que possibilita a prevenção à incrustação da membrana além de maximizar sua vida útil e dos demais componentes do sistema de tratamento.

\section{REFERÊNCIAS}

DHAR, R.; ZHENG, Y.; RUBENSTONE, J.; VAN GEEN, A. A rapid colorimetric method for measuring arsenic concentrations in groundwater. Analytica Chimica Acta, v. 526, n. 2, p.203-209, 2004.

DRIOLI, E.; ALI, A.; MACEDONIO, F. Membrane distillation: Recent developments and perspectives. Desalination, n. 356, p. 56-84, out. 2014.

KUNZ, A.; PERALTA-ZAMORA, P. Novas tendências no tratamento de efluentes têxteis. Química Nova, v. 25, p. 78-82, n. 1, 2002.

QU, D.; WANG, J.; HOU, D.; LUAN, Z.; FAN, B.; ZHAO, C. Experimental study of arsenic removal by direct contact membrane distilation. Journal of Hazardous Materials, v. 163, n. 2-3, p. 874-879, 009. 